Published online 2017 April 13.

Abstract

\title{
Statistic Method for Spine Vertebral Fracture Possibility
}

\author{
Ali Akbar Khadem, ${ }^{*}$ and Jalal Jalal Shokouhi ${ }^{1}$ \\ ${ }^{1}$ Jaam E Jam Medical Center \\ "Corresponding author: Ali Akbar Khadem. E-mail: khadem53@gmail.com
}

Received 2016 December 21; Accepted 2017 February 08.

\begin{abstract}
Radiology and imaging data of patient is the main and the most important data of the patient. Not only it shows disease of patient, but also it is included of the body geometry such as 2D and 3D. Gathering and saving of radiology images and data for different patients can be useful for future statistic studies. Many questions like, how to, why, in which and etc can be answered by statistic method, if we have had enough information in our hand. In this study we are going to find possibility of fracture in vertebra using statistic method. Radioogle web site was prepared as an search engine to gather information, searching data and result. By this method, the result extracted and show which vertebra are about to harm in case of fracture. The result shows that L1 is the most and L2, L4, L5 and C2 are the next possible to fracture in impact and accident. Other disease of spine and hierarchy in vertebra will be futuristic discussion.
\end{abstract}

Keywords: Radioogle, Statistic Method, Fracture Frequency

This is an abstract presented in the 33rd Iranian congress of radiology (ICR) and the 15th congress of Iranian radiographic science association (IRSA). 